\title{
Leaf morphology of progenies in $Q$. suber, $Q$. ilex, and their hybrids using multivariate and geometric morphometric analysis
}

\author{
Unai López De Heredia, \\ María José Duro-García, \\ Álvaro Soto
}

\begin{abstract}
The genus Quercus is known for the occurrence of frequent hybridization events between species. Although this phenomenon is not common among holm oak ( $Q$. ilex) and cork oak ( $Q$. suber), these species can hybridize when they coexist in mixed stands. The result of hybridization is a viable hybrid progeny with very heterogeneous leaf morphology. Literature concerning the leaf morphology of suber-ilex hybrid seedlings is scarce, and non-existent from a quantitative point of view. In the case of the leaf morphology of hybrids and their progeny, it has been observed a high frequency of leaves with fluctuating asymmetry or developmental abnormalities, which can have a marked effect on fitness. In this work, we have characterized seedlings' leaf morphology corresponding to two- and four-year-old half-sib progenies of holm oak, cork oak and their hybrids. For this purpose, three to ten leaves of each individual were collected, and two methodologies were used for analysis. Firstly, we used a classic morphological analysis of twelve variables that were reduced using multivariate techniques. On the other hand, shape of the leaves was thoroughly analyzed by geometric morphometric analysis methods. The extent of fluctuating asymmetry and the presence of developmental abnormalities of seedlings were analyzed calculating an asymmetry index. The results indicate that thickness is the most discriminating trait between species, and that the hybrid progenies do not show a third different phenotype compared to the parental species. However, half-siblings tend to show similar leaf morphology between them, depending on the genetic adscription of the parents. While fluctuating asymmetry was found in half-sib progenies of the parental species and the hybrids, a significant proportion of hybrid half-sibs showed strong leaf asymmetry, probably due to modifications of the epigenetic systems that control leaf development at the shoot apical meristems and leaf primordia.
\end{abstract}

Keywords: Hybridization, Fluctuating Asymmetry, Leaf Morphology, Procrustes Analysis

\section{Introduction}

Quercus suber and Q. ilex are two Mediterranean oak species that are included into different subgeneric groups (Ilex and (erris), and can be easily distinguished according to phenotypic traits of bark, cupules of the acorns, or leaves (Amaral Franco 1990). However, when both species occur in sympatric populations in the siliceous or decarbonated areas from the
Western Mediterranean, they hybridize, and individuals with intermediate or mixed phenotypes can be found in natural populations (Laguna 1881).

These hybrids are able to produce viable acorns when pollinated by $Q$. suber, or by Q. ilex (López De Heredia et al. 2017). The seedling stage is crucial for plant population dynamics due to its higher vulnerability to environmental constraints in compar-
GI Genética, Fisiología e Historia Forestal, Dept. Sistemas y Recursos Naturales, ETSI Montes, Forestal y del Medio Natural, Universidad Politécnica de Madrid (Spain)

@ Unai López De Heredia (unai.lopezdeheredia@upm.es)

Received: Jul 31, 2017 - Accepted: Oct 28, 2017

Citation: López De Heredia U, Duro-García MJ, Soto A (2018). Leaf morphology of progenies in $Q$. suber, $Q$. ilex, and their hybrids using multivariate and geometric morphometric analysis. iForest 11: 90-98. - doi: 10.3832/ifor2577-010 [online 2018-01-31]

Communicated by: Piermaria Corona ison with seed and adult stages (Harper 1977). Provided the low hybrid frequency found at the adult stage in natural populations (Burgarella et al. 2009), the question arises whether hybrid seedlings have different phenotypes to those of the parental species; and, if so, whether those different phenotypes may involve a more reduced fitness of hybrid seedlings.

The detection of hybrids in the field could be masked by the way the phenotypic characters segregate in the the first generation of offspring (F1), and subsequent generations. The phenotypic analysis of $\mathrm{F} 1$ hybrids in 46 plant taxa showed $44.6 \%$ of intermediate characters, while $45.2 \%$ of the characters in hybrids were similar to either parental species, and $10.2 \%$ presented transgressive characters (Rieseberg \& Ellstrand 1993). For the Q. ilex - Q. suber complex, a recent study has approached the molecular characterization of seedlings of Q. ilex, Q. suber, and Q. ilex $\times$ suber progenies grown in nursery conditions in three different years (López De Heredia et al. 
Tab. 1 - Number of analyzed plants by cohort, species and family.

\begin{tabular}{llrr}
\hline \multirow{2}{*}{ Species } & \multirow{2}{*}{ Family } & \multicolumn{2}{c}{ Cohort } \\
\cline { 2 - 4 } & & $\mathbf{2 0 1 2}$ & $\mathbf{2 0 1 4}$ \\
\hline Hybrids & LG1 & 21 & 38 \\
& LG2 & - & 5 \\
& IS & 59 & 77 \\
& ZLR & 19 & 14 \\
\cline { 2 - 4 } Q. ilex & Total & 99 & 134 \\
& I1 & 19 & 5 \\
& I2 & 9 & 4 \\
& I3 & - & 4 \\
& I4 & - & 3 \\
\cline { 2 - 4 } Q. suber & Total & 28 & 16 \\
& S1 & 8 & 2 \\
& S2 & 11 & 4 \\
& S3 & - & 4 \\
& S4 & - & 4 \\
\cline { 2 - 3 } & Total & 19 & 14 \\
\hline
\end{tabular}

2017). The quantitative analysis of phenotypes on these progenies, specifically of leaf morphological traits, may shed light on the way these characters segregate in relation to the specific category of the seedlings previously estimated.

Leaf morphology plays an important role in species adaptations related to photosynthetic ability of plants: heat dissipation, light interception and hydraulic resistance, among others, and is crucial in early stages of seedling growth (Valladares \& Niinemets 2008). The relationship of leaf morphological traits and the specific categories of hybrid oaks determined with molecular markers has been widely studied in natural populations (Kremer et al. 2002). Leaf traits are extremely variable between and within populations, and even among branches within a tree (Bruschi et al. 2003). Moreover, significant ontogenetic (Kleinschmit et al. 1995) and seasonal (Blue \& Jensen 1988) variation have also been reported. Therefore, in order to reduce bias and obtain sound results, leaf morphological approaches should be performed in controlled conditions on known pedigree individuals, or on controlled crosses or field trials (Gugerli et al. 2007). However, to our knowledge, the analysis of leaf morphology of hybrid seedlings of different age has not been addressed in the Q. ilex - Q. suber complex.

One of the undesired effects of hybridization on leaf morphology is the yielding of asymmetries in the lamina that may have an effect on seedling stability and fitness when they are of great magnitude (Parsons 1990). According to the intensity and causes of leaf distortions, two types of asymmetries have been described for oak leaves: (i) fluctuating asymmetry that consists of small random variations in the right and left sides of a bilateral trait that deviate from perfect symmetry (Graham et al. 2010), which is usually related to environmental variation in oaks (Hódar 2002, Puerta-Piñero et al. 2008, Viscosi 2015), but also to genotypic variation (Albarrán-Lara et al. 2010); and (ii) strong asymmetries produced by cytonuclear inconsistence or (epi)genetic stress during leaf blade differentiation (Lodha et al. 2013). Both types of asymmetry may increase with hybridization and introgression (Wilsey et al. 1998, Albarrán-Lara et al. 2010).

Therefore, the specific aims of present study were: (i) to quantify developmental and fluctuating asymmetry in hybrid progenies; (ii) to characterize the leaf morphology of two and four year-old progenies from open pollinated $Q$. ilex $\times Q$. suber mother trees; (iii) to identify the factors (cohort, species, family, genotype) accounting for variation in leaf morphological traits; and (iv) to inspect the correlation of morphological variables and previously inferred specific assignation of seedlings.

\section{Material and methods}

\section{Experimental design}

The sampling site is a mixed dehesa, i.e., a highly anthropised open woodland, located in Central Spain ( $39^{\circ} 59^{\prime} \mathrm{N}, 5^{\circ} 7^{\prime} \mathrm{W}$ ). Four mature hybrids were identified according to their phenotypes. The hybrids occur in three areas of contrasting density and specific composition: (1) "La Isla" (Is), where Q. ilex and Q. suber mix at a density of 38 trees ha", being Q. suber slightly more abundant; (2) "La Laguna" (LG), a low density area (20 trees ha ${ }^{-1}$ ) dominated by $Q$. ilex, where two hybrids co-occur; and (3) $\mathrm{ZL}$, which is a denser area of 123.5 trees ha $^{-1}$ (38.3 trees ha ${ }^{-1}$ for Q. ilex and 85.2 trees ha ${ }^{-1}$ for Q. suber).

To obtain open pollinated, half-sib progenies, acorns were collected from the canopy of the four hybrids, in November 2012, and 2014. In addition, acorns were also collected from two Q. ilex, and four Q. suber individuals in 2012, and from two $Q$. ilex and two Q. suber individuals in 2014, respectively. The sampling scheme is detailed in Tab. 1. The full sampling scheme and the procedure to obtain half-sib families of seedlings is detailed in López De Heredia et al. (2017).

In January 2016, three to ten (mean $=5.4$; s.d. $=2.86$ ) fully-developed leaves were collected from the surviving 2012 (1361 leaves) and 2014 (1631 leaves) seedlings. Leaves were collected in alternate position along the entire stem. Leaves were dried in a plant press and scanned for further analysis, always visualizing the abaxial side of the leaf. The specific category of each seedling was assessed by the value of the $q_{\mathrm{s}}$ parameter obtained with the Bayesian procedure implemented in the software Structure (Pritchard et al. 2010) for eight nuclear microsatellite genetic data as implemented in Burgarella et al. (2009) (López De Heredia et al. 2017).

\section{Fluctuating and developmental leaf asymmetry}

Fluctuating and developmental leaf asym- metry were investigated using semi-automated measures of the leaf surface in the right and left sides that were performed with the software Image (Abramoff et al. 2004). Further, an asymmetry index was computed for each leaf as follows (eqn. 1):

$$
L S A I=\frac{|L S-R S|}{L S+R S}
$$

where LS is the surface of the left side of the leaf lamina and RS is the surface of the right side of the leaf lamina. For LSAI < 0.05 , leaves are symmetrical; for $0.05<$ $L S A I<0.2$, leaves show fluctuating asymmetry; and for LSAI >0.2, leaves present strong asymmetries related to developmental anomalies.

The frequency of plants showing leaf fluctuating asymmetry was quantified by a fluctuating seedling asymmetry index defined as (eqn. 2):

$$
F S A I_{i}=\frac{N_{i}^{\prime}}{N_{i}}
$$

where $N_{i}^{\prime}$ is the number of leaves of seedling $i$ with a LSAI value ranging between 0.05 and 0.2 , and $N_{i}$ is the measured number of leaves of seedling $i$.

The frequency of plants showing strong asymmetries related to development was quantified by a developmental seedling asymmetry index defined as (eqn. 3):

$$
D S A I_{i}=\frac{N_{i}^{\prime \prime}}{N_{i}}
$$

where $N^{\prime \prime}$ is the number of leaves of seedling $i$ with a LSAI value higher than 0.2, and $N_{i}$ is the measured number of leaves of seedling $i$.

\section{Leaf morphological multivariate analysis}

Twelve leaf morphological traits were measured for multivariate analysis. Dried leaves were weighed with a precision balance to estimate dry weight (DW). The thickness of the leaf lamina $(T)$ was estimated as the mean value of four measurements at different points of the lamina. The number of teeth (NT) was manually counted and log-transformed to achieve normality. The remaining nine leaf traits were automatically obtained from scanned leaves with the image analysis system WinFolia $^{\mathrm{TM}}$ (Regent Instruments Inc., Canada), and were the following (Fig. 1a): leaf lamina perimeter $(P)$; leaf lamina surface $(S)$; leaf total length (L); leaf width at $50 \%$ of leaf total length (W); leaf lamina length (LL); leaf lamina maximum width (WM); petiole length $(\mathrm{PL})$; ratio between the leaf lamina maximum width and the leaf lamina length (WM/LL); a shape coefficient (SH) estimated as $4 \Pi S / \mathrm{P}^{2}$. Measures on leaves that showed strong asymmetries, i.e., leaves with LSAI > 0.2 were discarded from further analyses.

Median, mean, maximum/minimum val- 
ues and standard deviation were scored for each variable at family, species and cohort levels, respectively. A principal component analysis (PCA) was performed by scaling the original variables with the "princomp" command from the R 3.3.1 "stats" package (R Core Team 2016). The two principal components (PCs) explaining most of the total variance were selected. New variables were created from the scores of the components, thus simplifying further analysis. The mean scores by individual of the first two principal components were biplotted to graphically inspect differences between species, and one-way ANOVAs were performed for this factor. Post-hoc comparisons were performed in order to determine the differences between levels of the specific factor. Tukey's HSD (Honestly Significant Difference) test was performed with the "HSD.tsts" function from the "agricolae" library (Mendiburu \& Simon 2015) of $R$ package.

Leaf morphometric geometric analysis

Landmark-based morphometric geometric analysis provides a deeper insight on leaf shape variation than the analysis of the shape coefficient $\left(4 \Pi S / \mathrm{P}^{2}\right)$ and the ratio between the leaf lamina maximum width and the leaf lamina length (WM/LL) of the standard morphological multivariate analysis (Bonhomme et al. 2014). The geometric morphometric analysis was conducted using the software LeafAnalyser (Weight et al. 2008) upon the scanned leaves. To obtain $2 \mathrm{D}$ landmarks as $\mathrm{X}-\mathrm{Y}$ coordinates it is necessary to define two reference points in the leaf (Fig. 1b): (i) a centroid that was automatically computed by the software using the mean of all the $X-Y$ coordinates of all pixels within the leaf margin; and (ii) the leaf apex, so the leaf is oriented. Forty-nine additional equidistant points were defined along the leaf margin, for which their respective $X-Y$ coordinates were scored.

Once the $X-Y$ coordinates were scored, we used the "gpagen" function from the "geomorph" library (Adams \& Otárola-Castillo 2013) in R 3.3.1 to perform Procrustes superimposition (Rohlf \& Slice 1990). Generalized Procrustes Analysis translates all landmark configurations to a common location, re-scaling all to unit centroid size, and rotating all into an optimal leastsquares alignment with an iteratively estimated mean reference shape. These transformations minimize the differences in location between compared landmark data.

A Principal Component Analysis was performed with the "plotTangentSpace" function and the first two principal components were bi-plotted to visualize differences between groups. The "morphol.disparity" function was used to estimate the morphological disparity between cohort, species and families, respectively, as the Procrustes distance, and the significance of differences among groups was estimated through a p-value.

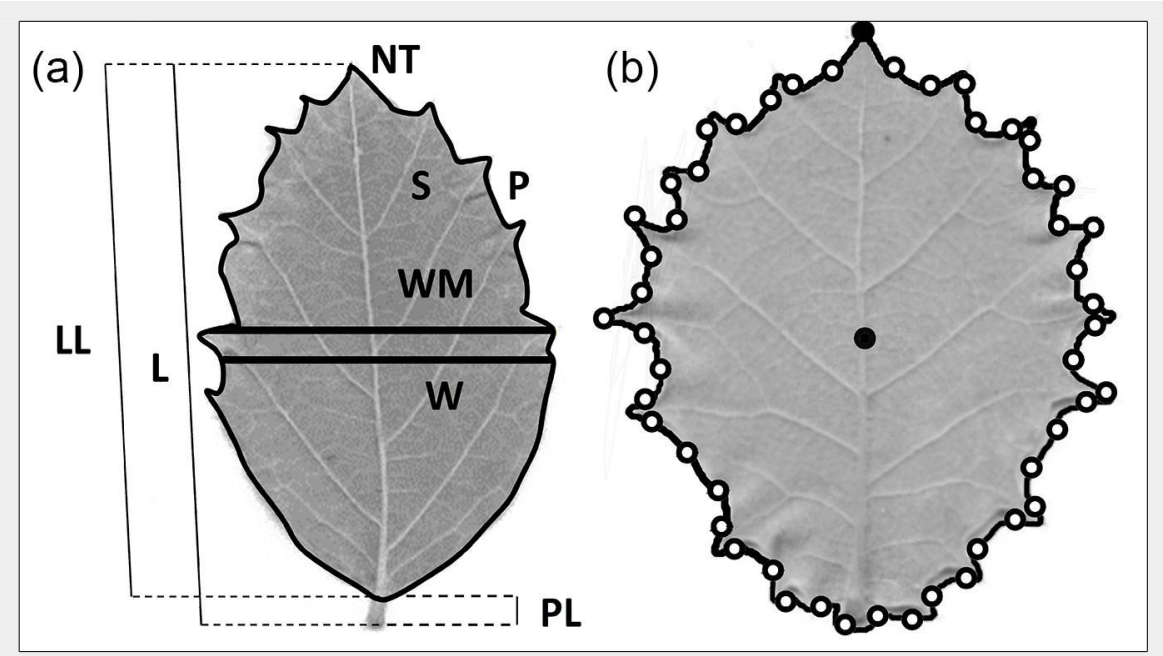

Fig. 1 - (a) Leaf variables measured for multivariate analysis with the image analysis software WinFolia ${ }^{\mathrm{TM}}$. (b) Schematic position of leaf apex and centroid (full black dots), and landmarks (empty black dots) for morphometric geometric analysis of shape determined with the software LeafAnalyser.

\section{Mixed effects linear models and} variance components estimations

Based upon the new variables (i.e., principal components scores) that mostly contributed to the overall variation for both morphological and morphometric geometric analysis, mixed effects linear model considering the cohort as a fixed effect and species (Q. suber, Q. ilex and hybrids), family and plant as nested factors as random effects were built with the "Ime" function of the "nlme" library (Pinheiro et al. 2017) of $R$ package. The model was the following (eqn. 4):

$$
Y_{i j k l m}=\mu+\alpha_{i}+\beta_{j}+\gamma_{k(j)}+\delta_{l(k(j))}+\varepsilon_{i j k l m}
$$

where $\mu$ is the mean of the principal component, $\alpha_{\mathrm{i}}$ is the effect of cohort $i, \beta_{\mathrm{i}}$ is the effect of species $j, \gamma_{\mathrm{k}(\mathrm{)})}$ is the effect of the family $k$ within species $j, \delta_{1(k(j))}$ is the effect of the plant I within family $k$ within species $j$, and $\varepsilon_{i j k l m}$ is the terms the error $(E)$.

All the random factors showed a normal distribution as follows: $\beta_{\mathrm{j}}: \mathrm{N}\left(0 ; \sigma_{\mathrm{s}}\right) ; \gamma_{\mathrm{k}(\mathrm{j})}: \mathrm{N}(0$;

Tab. 2 - Contribution of the measured variables to the first three principal components. (*): variables that contributed most to each PC.

\begin{tabular}{llll}
\hline Variable & \multicolumn{1}{c}{ PC1 } & \multicolumn{1}{c}{ PC2 } & PC3 \\
\hline NT & -0.54505911 & 0.57133737 & 0.06719112 \\
DW & $-0.94474033^{*}$ & 0.02529156 & -0.0277579 \\
T & 0.00236017 & $0.83459101^{*}$ & 0.05697182 \\
S & $-0.95021391^{*}$ & -0.2347433 & -0.04317772 \\
P & $-0.96134823^{*}$ & 0.12877999 & 0.05231506 \\
L & $-0.9329851^{*}$ & -0.23694868 & 0.09173586 \\
W & $-0.964661^{*}$ & -0.05444766 & -0.11786569 \\
LL & $-0.93677664^{*}$ & -0.23051776 & 0.08068672 \\
WM & $-0.96422764^{*}$ & -0.05474921 & -0.11193033 \\
PL & -0.58461261 & -0.06033392 & -0.02877686 \\
WM_LL & -0.0613093 & 0.22895923 & $-0.95775912^{*}$ \\
SH & 0.51759531 & -0.63655759 & -0.22501442 \\
\hline
\end{tabular}

$\left.\sigma_{\mathrm{S}(\mathrm{F})}\right) ; \delta_{\mathrm{l(k( \textrm {j } )})}: \mathrm{N}\left(\mathrm{o} ; \sigma_{\mathrm{S}(\mathrm{F}(\mathrm{P}))}\right) ;$ and $\varepsilon_{\mathrm{ijk} \mid \mathrm{m}}: \mathrm{N}\left(\mathrm{o} ; \sigma_{\mathrm{E}}\right)$. tain estimators of the random terms of the model $\sigma_{(\mathrm{S})}, \sigma_{\mathrm{S}(\mathrm{F})}, \sigma_{\mathrm{S}(\mathrm{F}(\mathrm{P}))}$, and $\sigma_{\mathrm{E}}$ for PC1 (size), PC2 (thickness) and PC1.shape (shape) using the restricted maximum likelihood method to identify the factors that contribute significantly to variation in the principal components of the model above.

\section{Correlation of leaf morphology with} genetic specific category parameters Correlations between the mean principal component scores obtained for morphological and morphometric geometric analyses and the specific category of hybrid seedlings and inferred fathers, estimated as the $q$ values obtained from Bayesian analysis from microsatellite data (López De Heredia et al. 2017), were calculated with Pearson's $r$ coefficient using the "cor" function of R. Linear models were fitted for the principal component scores that showed high correlation values. The "varcomp" command was used to ob- 
Fig. 2 - Biplot of the mean individual scores for the first two PCs for the morphological multivariate analysis, and Tukey's HSD tests for (b) PC1 (size), and (c) PC2 (thickness). (Green): Q. suber; (red): Q. ilex; (black): hybrids. Groups with the same color in the bar diagrams do not show significant differences in their means.

(b)

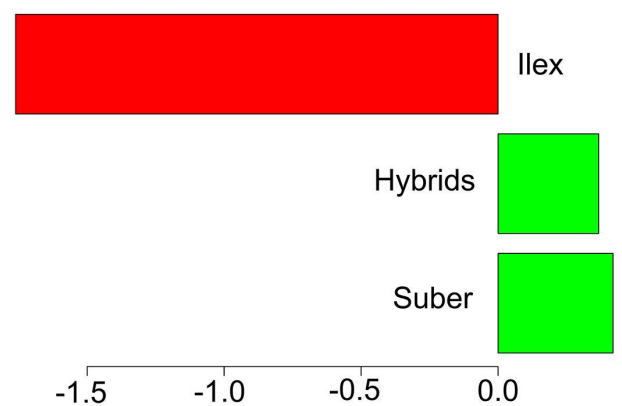

(c)
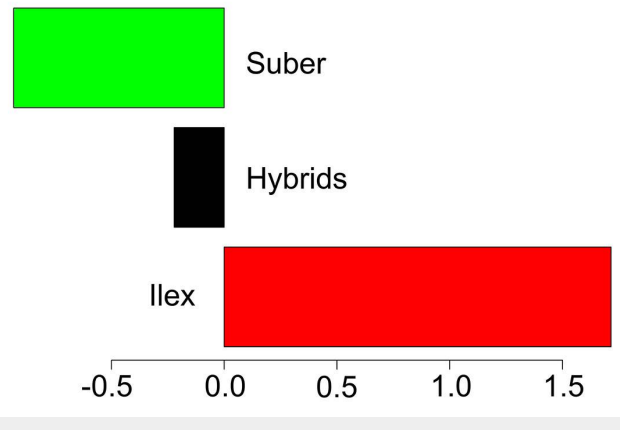

\section{Results}

Leaf fluctuating and developmental asymmetry

Fluctuating asymmetry was detected for a significant percentage of the seedling progenies, irrespective of the parental specific category. According to the results of the $F S A I_{i}$ parameter, evidence of fluctuat-

ing asymmetry was obtained for leaves of Q. suber, Q. ilex, and hybrid progenies in very similar proportions (Fig. S1a in Supplementary material). A closer examination of the distribution of fluctuating asymmetry for the hybrids progenies revealed that there were slight differences between seedlings of different cohorts depending on the family to which the plants belong

Tab. 3 - ANOVA results for the fixed effects (cohort) of the linear mixed effects models (eqn. 4) fitted for the principal component scores related to leaf size (PC1), leaf thickness (PC2), and leaf shape (PC1.shape). (df): degrees of freedom; (SS): sum of squares; (MS): mean squares; $(* * *): p<0.001$.

\begin{tabular}{llrrrc}
\hline Scores & Effect & \multicolumn{1}{c}{ df } & \multicolumn{1}{c}{ SS } & MS & F-value \\
\hline PC1 (size) & $\alpha_{\mathrm{i}}$ (cohort) & 1 & 2210 & 2209.7 & $342.2^{* * *}$ \\
& Residuals & 2819 & 18203 & 6.5 & - \\
\hline PC2 (thickness) & $\alpha_{\mathrm{i}}$ (cohort) & 1 & 1060 & 1059.6 & $817.3^{* * *}$ \\
& Residuals & 2819 & 3655 & 1.3 & - \\
\hline PC1.shape & $\alpha_{\mathrm{i} \text { (cohort) }}$ & 1 & 0.43 & 0.4301 & $78.98^{* * *}$ \\
& Residuals & 2755 & 15.00 & 0.0054 & - \\
\hline
\end{tabular}

(Fig. S1b, Fig. S1c, Fig. S1d). Actually, there were no significant differences between cohorts for the Is progeny $(F=0.65, p$ value $=0.421)$, and only slight, yet significant, differences were scored for the LG1 $(F=5.95, p$-value $=0.0179)$, and $Z L(F=8.17$, p-value $=0.0075$ ) families.

Strong asymmetries of diverse nature (Fig. S2 in Supplementary material) related to developmental anomalies were detected for $29.9 \%$ of all seedlings. This type of asymmetry was almost an exclusive character of the hybrid progenies, with only a single Q. ilex individual showing leaf asymmetry (Fig. S3a). In this case, however, strong differences in the frequency of asymmetric leaves were scored between two and four year-old seedlings of the hybrid progenies, specially for IS ( $F=42.34$, $\mathrm{p}$ value $<0.0001-$ Fig. S3b), and to a less extent for $Z L(F=2.184$, $p$-value $=0.145-$ Fig. S3d) families. For LG family, although the boxplots suggest that there were differences between cohorts (Fig. S3C), these differences were not significant $(F=6.542$, $\mathrm{p}$-value $=0.0156)$. In all three cases, higher proportion of asymmetric leaves was detected for two than for four year-old seedlings.

\section{Leaf morphological multivariate analysis}

After removing asymmetric leaves related to developmental anomalies, the first three principal components explained $82.2 \%$ of total variance. The variables that mostly contributed to the two first principal components were related to size (DW, dry weight; $\mathrm{S}$, surface; $\mathrm{P}$, perimeter; $\mathrm{L}$, total length; $W$, leaf width at $50 \%$ of leaf total length; LL, lamina length; and WM, leaf lamina maximum width) for $P(1$, and to leaf thickness ( $T$ ) for PC2 (Tab. 2). The variables that mostly contributed to $\mathrm{PC}_{3}$ were related to leaf shape (WM LL, ratio between the leaf lamina maximum width and the leaf lamina length - Tab. 2). However, PC3 only explained $8.3 \%$ of the total variance, so it was not considered in further analysis. Indeed, variation in shape is better captured using morphometric geometric analysis than with the WM_LL variable (see below).

The biplot of the mean individual scores for PC1 and PC2 showed significant differences between Q. ilex and Q. suber progenies (Fig. 2a). For $P C 1$, negative values indicate bigger leaves ( $Q$. ilex), while positive values point to leaves of smaller size ( $Q$. suber). While seedlings of hybrid families showed high variability in leaf size, there were non-significant differences among means with leaves of $Q$. suber seedlings, at the same time that both were significantly different than leaves of Q. ilex progenies, according to the HSD Tukey's tests (Fig. 2b). For PC2, Q. ilex progenies showed positive values, and therefore thicker leaves, while Q. suber progenies presented negative values. Interestingly, for this character, hybrid progenies showed intermediate val- 
ues that were significantly different from both Q. ilex and Q. suber progenies.

Leaf morphometric geometric analysis The principal component analysis of the landmark coordinates after Procrustes transformation showed that the two first components accounted for $56 \%$ of overall variance. Actually, the first component (PC1.shape) explained $44.8 \%$ of the overall variance. Although the mean scores for the three specific categories overlapped to some extent, the biplot of the mean individual scores for PC1.shape and PC2.shape, showed significant differences between the progenies of Q. ilex and Q. suber along the PC1.shape axis (Fig. 3). The hybrid families presented intermediate or similar values to Q. suber progenies for this component related to shape.

\section{Mixed effects linear models and}

variance components estimations

The fitted models showed significant differences between two and four year-old seedlings for the three principal components related to size, thickness, and shape of the leaves (Tab. 3). However, these differences were more evident for size and thickness (Fig. S4a in Supplementary material) than for shape (Fig. S4b). The random terms of the models, however, showed different impact of each factor depending on the morphological trait, as estimated from the variance components (Fig. S5). The term species $\left(\beta_{\mathrm{i}}\right)$ explained high variance percentages for leaf thickness ( $51.1 \%)$, and

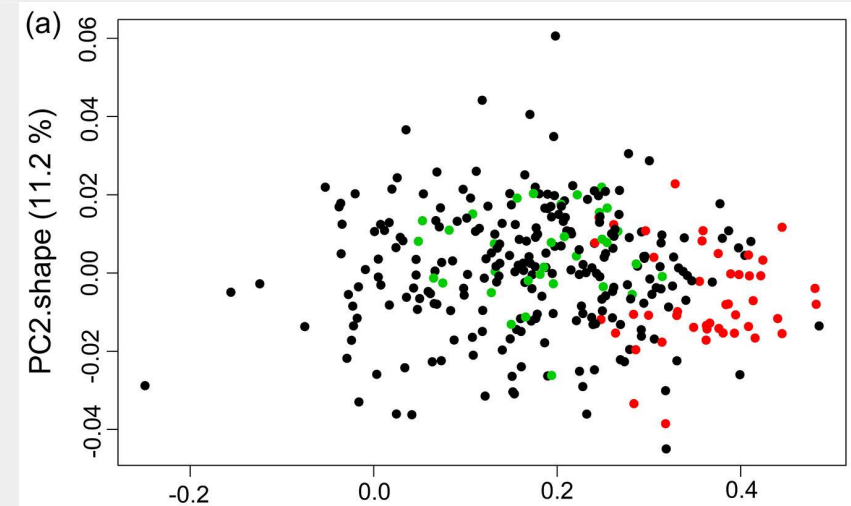

(b)

PC1.shape (44.8\%)

Fig. 3 - Biplot of the mean individual scores for the first two PCs for the morphometric geometric analysis, and Tukey's HSD tests for PC1.shape. (Green): Q. suber; (red): Q. ilex; (black): hybrids. Groups with the same color in the bar diagrams do not show significant differences in their means.

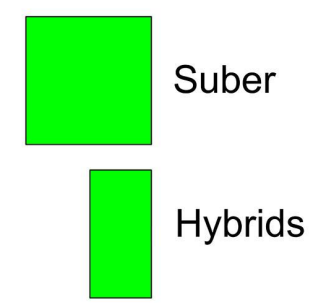

Ilex

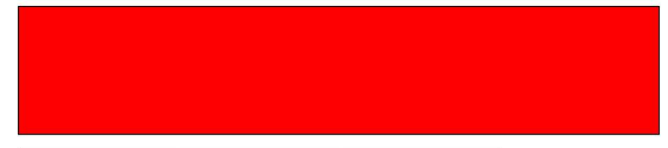

0.00

0.02

0.04

0.06

leaf shape (33.2\%), consistent with the re- variance was found for species, while high sults of the principal component analysis. variance percentages were scored due to For leaf size, however, less percentage of variation within plants $\left(\varepsilon_{\mathrm{ijkl}}, 37.8 \%\right)$, and be-

Fig. 4 - Linear models fitted for the $q_{s}$ parameter obtained for the seedlings vs. the mean individual values of $\mathrm{PC} 1$ (size), PC2 (thickness) and PC1.shape

(shape) for Is, LG1, and ZL families. (Black dots): 2012 seedlings; (red dots): 2014 seedlings.

(a)

Is

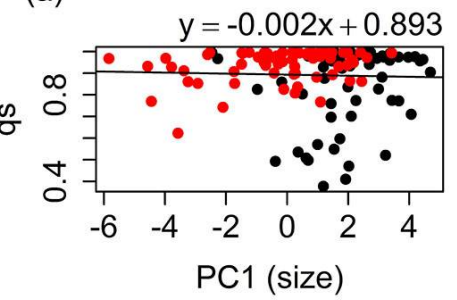

Is

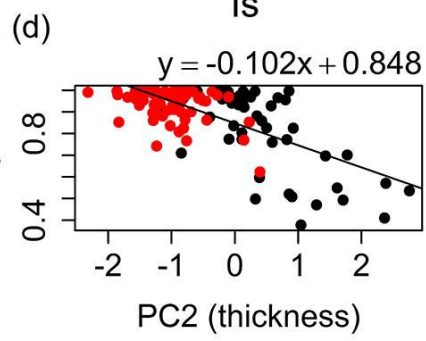

(g)

Is

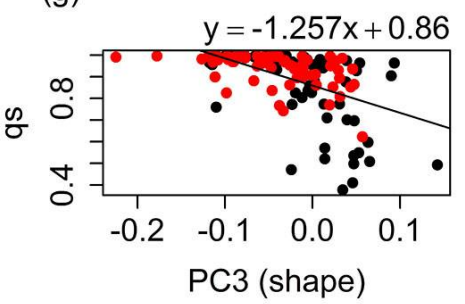

(b)

LG1

음

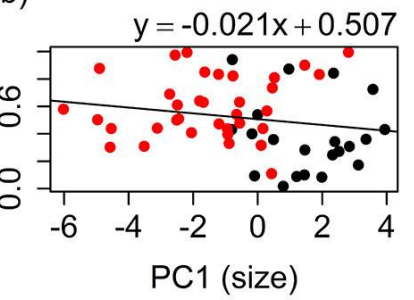

LG1

(e)

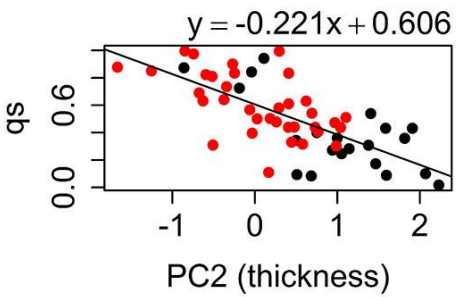

(h)

LG1

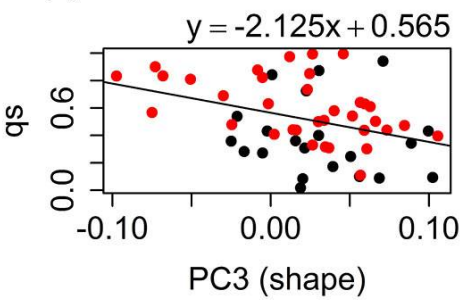

(c)

ZL

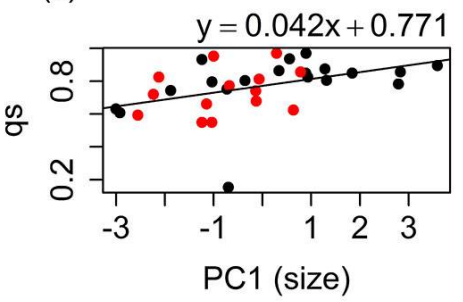

(f)

ZL

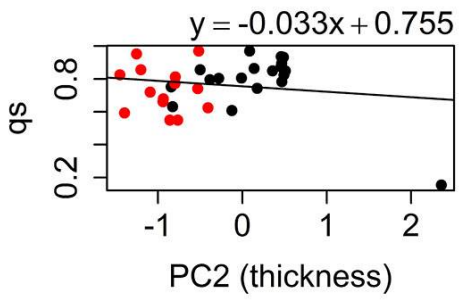

(i)

ZL

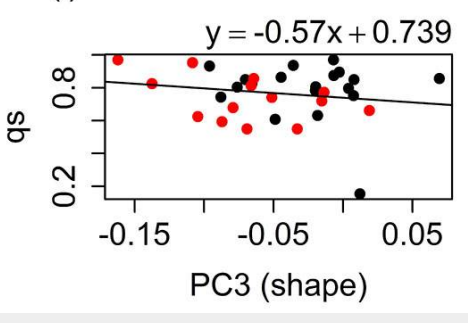



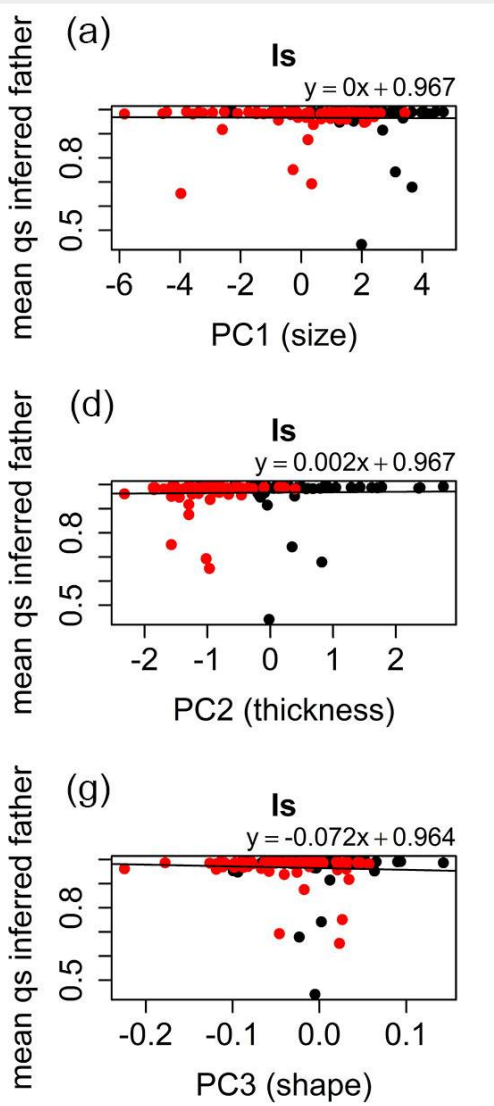
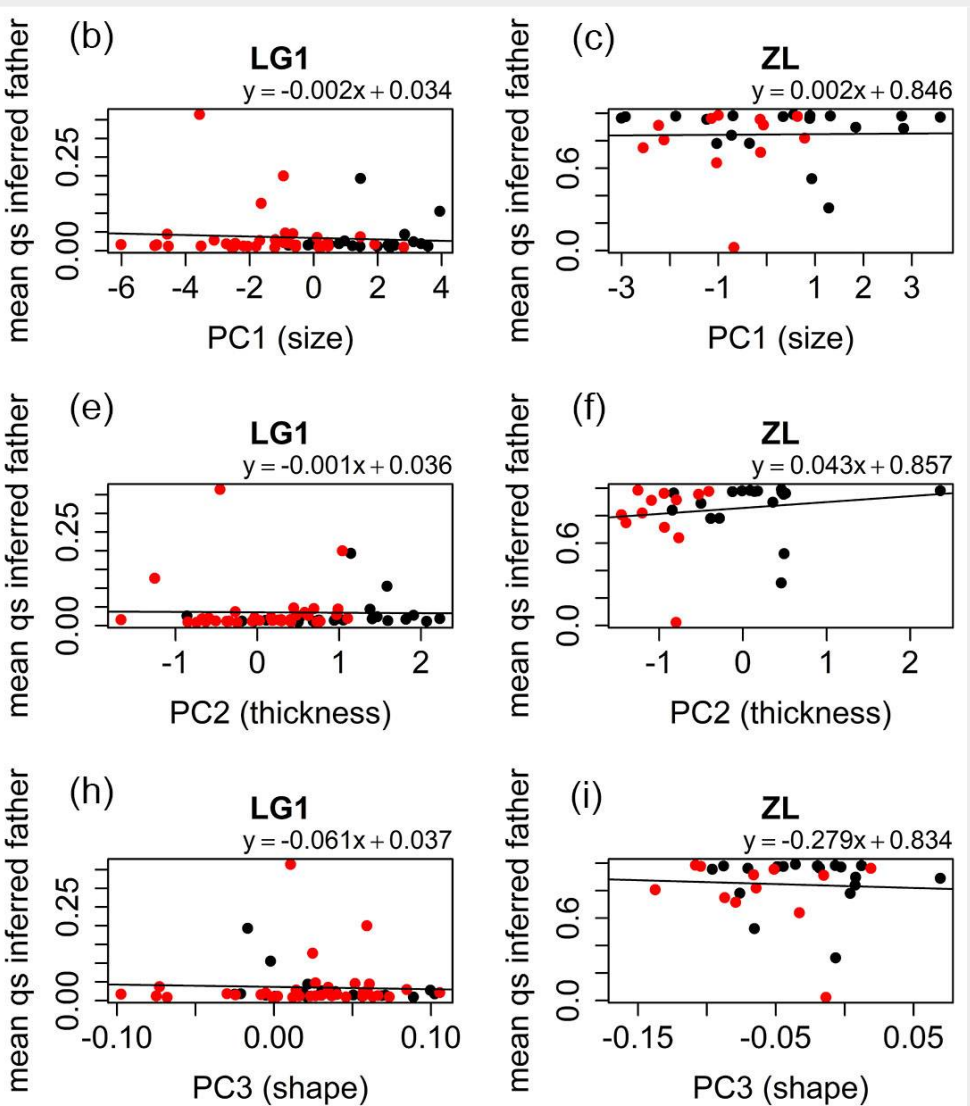

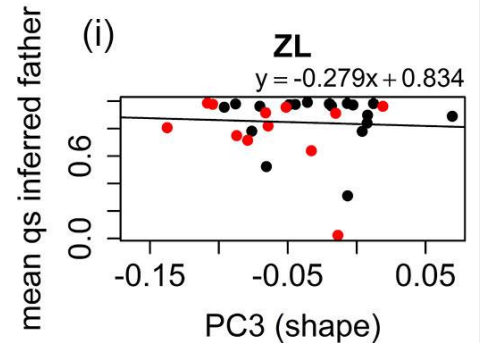

tween plants within families within species $\left(\delta_{\mid(k(i))}, 38.2 \%\right)$. Interestingly, the percentage of variance explained by the term family within species $\left(\gamma_{\mathrm{k}(\mathrm{i})}\right)$ was small for the three principal components.

\section{Correlation of leaf morphology with} genetic specific category parameters

For the Is and LG1 families strong significant negative correlations were found between leaf thickness $(P C 2)$ and $q_{s}$ values of the seedlings estimated with Structure (Is: $r=-0.67, p$-value < 0.001; LG1: $r=-0.71$, $p$ value $<0.001$ - Fig. $4 \mathrm{~d}$, Fig. $4 \mathrm{e}$ ), and between leaf shape ( $P C 1$.shape) and $q_{s}$ values (Is: $r=-0.51, p$-value < 0.001; LG1: $r=-0.36$, p-value $=0.006-$ Fig. 4g, Fig. 4h), respectively (López De Heredia et al. 2017). For leaf size (PC1), correlations were non-significant for the Is $(r=-0.03, p$-value $=0.705$ - Fig. 4a) and LG1 $(r=-0.18$, $p$-value $=0.163$ - Fig. 4b) families. For the ZL family, significant positive correlation was found between these two variables $(r=0.42, p-$ value $=0.015-$ Fig. 4c). However, only $a$ small part of the ZL samples $q_{\mathrm{s}}$ values below 0.5 , and therefore, this correlation needs to be interpreted with caution. This circumstance produced also non-significant correlations for the ZL family between leaf thickness $(r=-0.16$, p-value $=0.371)$ and shape $(r=-0.17$, $p$-value $=0.334)$, and the specific category (Fig. 4f, Fig. 4i). Correlation of the morphological characters with the inferred $q_{\mathrm{s}}$ values of the potential pollen donors was very low for all the halfsib families and cohorts (Fig. 5).

\section{Discussion}

\section{Leaf fluctuating and developmental} asymmetry

A high proportion of leaves with fluctuating and developmental asymmetries in seedlings was found in this study. However, the frequency of fluctuating and developmental asymmetry was variable between cohorts, species and families, supporting the hypothesis of factors of different nature operating on each type of asymmetry (Milligan et al. 2008).

The proportion of seedlings with leaves showing fluctuating asymmetry was high for the hybrid progenies, but also for the pure species' families. Determining the causes of fluctuating asymmetry for the seedlings of this study is not straightforward. Fluctuating asymmetry induction by changes in biotic and abiotic factors has been documented for oak species (PuertaPiñero et al. 2008, Viscosi 2015). Therefore an effect of small-scale heterogeneity in nursery conditions, both in water stress or in light-shade conditions, cannot be completely discarded. Large morphological and physiological variation has been acknowledged for Q. ilex leaves in relation to ecotypic variation at broad scales associated with water availability (Niinemets 2015, Peguero-Pina et al. 2014), and, specifically, fluctuating asymmetry in response to hydric stress was reported for Q. ilex (Hódar 2002). In addition, leaf structural plasticity in Q. ilex and Q. suber is a stronger determinant for leaf acclimation to incident photo- synthetic photon flux density than biochemical and physiological plasticity (Vaz et al. 2011); thus fluctuating asymmetry could be also generated by the structural adjustment of leaf structures during acclimation to changes in light intensity.

From studies in natural populations, it has been argued that the genotypic composition of the populations (Wilsey et al. 1998), and hybridization (Albarrán-Lara et al. 2010) may produce fluctuating asymmetry. However, no significant differences in the frequency of fluctuating asymmetry between Q. ilex, Q. suber, and hybrid seedlings were scored with the $F S A I_{i}$ index in the present study. While fluctuating asymmetry is more likely due to environmental stress than to hybridization, the strong asymmetric patterns found only for hybrid progenies are associated to anomalies produced during leaf development.

Actually, leaf asymmetries are not the exclusive anomalies observed in hybrid progenies. Seedlings that lack leaves, seedlings with multiple stems or strong ramification patterns, and dwarf seedlings without apparent apical growth are also frequent. These types of malformations in hybrids have been described for other angiosperms (Takanashi \& Marubashi 2017), and are related to genetic incompatibilities that modify the epigenetic system controlling the differentiation of the apical shoot meristem and the leaf primordia (Lodha et al. 2013). Networks of genes coding for small RNAs and transcription factor-like proteins determine the polarity specification of flat 
bifacial leaves (Nicotra et al. 2011). Possibly, disruptions of regulatory networks due to interspecific genomic incompatibilities are responsible for producing abnormal phenotypes in Q. ilex $\times$ Q. suber progenies. As reported for the model species Arabidopsis, the repression of key genes that regulate the adaxial-abaxial polarity, such as ETT/ARF3, ARF4, and others that regulate the proximal-distal leaf length (class 1 KNOX homeobox genes - BP, KNAT2), produces asymmetric leaves (Matsumura et al. 2016).

The frequency of leaf asymmetries associated to development was significantly higher for two year-old seedlings than for four year-old seedlings. One possible explanation is that the modification of the epigenetic systems involved in the development of the foliar primordia produced by hybridization induces a higher degree of malformation in younger than in older plants. The few studies that have investigated the relationship between age and leaf anomalies suggest that leaf asymmetry decreased with age in leaves (Milligan et al. 2008). Alternatively, extremely asymmetric leaves may fall from the seedlings earlier, showing apparently shorter life-spans than normal leaves. However, for deciduous trees, leaf life span is independent of asymmetry (Kozlov 2003). Although not verified in field experiments, early expressed abnormality probably results in lower fitness of the hybrid seedlings, and in higher mortality rates than pure species. This could account for the low frequency of adult hybrid trees in mixed populations, no matter they produce high amount of viable acorns (López De Heredia et al. 2017).

\section{Leaf morphological variation in Q. ilex,} Q. suber seedlings

Both multivariate and morphometric geometric analyses allowed the leaf morphological characterization of the seedlings that did not present asymmetrical patterns. In our study, the best descriptors of leaf morphology for seedlings of Q. ilex and $Q$. suber are lamina size, thickness, and shape, being leaf thickness the most discriminant character between Q. ilex and Q. suber. This result is consistent with the higher tolerance of Q. ilex seedlings to high values of light irradiance as compared with Q. suber seedlings (Quero et al. 2006). Castro-Díez et al. (2000) showed, for a wide range of species, that the thicker mesophyll of evergreen seedling leaves was not due to cell wall thickening and sclerification, but a consequence of a larger number of cell layers to increase the photosynthetic capacity per area unit.

The significantly thicker leaves found for four year-old seedlings of both species from our study, matches with the increasing in thickness and leaf mass dry per unit area between cohorts reported for seedlings of the same species (Mediavilla et al. 2011). Furthermore, species with a long average leaf life span, Q. ilex in this case (Me- diavilla \& Escudero 2003), tend to have high leaf thickness and mass per unit area, low nutrient concentrations and show maximum photosynthetic rates (Poorter et al. 2009).

Quercus ilex presented also leaves of higher size than $Q$. suber seedlings. Leaf area is known to be a character of great plasticity in deciduous temperate trees (Sack et al. 2006, and references therein). This great plasticity was also described for evergreen species, such as Q. ilex (Mediavilla et al. 2012), and Q. suber (Cardillo \& Bernal 2006). Interestingly, leaf size from adult trees is traditionally described as following the opposite pattern, i.e., adult $Q$. ilex has smaller leaves than adult Q. suber (Amaral Franco 1990). Actually, two yearold seedlings presented bigger leaves than four year-old seedlings. This seems to be an exception for evergreen species, because although leaf size varies across ontogenetic stages (Poorter 2007), linear allometric relationships during ontogenetic development are expected (Cornelissen 1999). Other authors, however, have reported that the increments in leaf mass per unit area as the seedling increases, seem to be achieved only through increased thickness, with no associated changes in density (Mediavilla et al. 2012), and therefore, no impact on leaf surface.

The morphometric analysis showed significant differences between the leaf shape of Q. ilex and Q. suber seedlings. Leaves of Q. ilex seedlings show suborbicular shape, while Q. suber seedlings present ovate leaves (Amaral Franco 1990). Leaf shape is highly dependent on general regulators of shoot apical meristem and cell cycling in the initial stages of leaf development (Barkoulas et al. 2007), and, during the last stages, is adjusted by the environmental conditions (Tsukaya 2005). In this case, leaf shape showed very slight differences between seedlings of both cohorts, suggesting that it is a more stable character than size or thickness. Indeed, leaf shape is less variable across environments than size (McDonald et al. 2003).

\section{Segregation of morphological traits of hybrid progenies}

Hybrid seedlings presented very diverse phenotypes that may resemble the phenotypes of pure species, or present transgressive traits possibly due to epistasis, heterosis and/or developmental instability (Rieseberg \& Ellstrand 1993). Leaf traits related to size, thickness, and shape showed independent segregation patterns in hybrid progenies. The correlation between the mean scores of the principal components related to size, thickness and shape, and the genetic category $\left(q_{s}\right)$ of the hybrid offspring is rather high (Fig. 4), particularly for those hybrid families that presented a wide spectrum of $q_{s}$ values (Is, LG1). On the contrary, correlation with the $q_{\mathrm{s}}$ of the potential fathers is rather poor (Fig. 5), suggesting a maternal effect in the leaf characters of the seedlings. However, the mixed model did not detect a significant effect of the maternal genotype for any trait.

Leaf growth traits often show intermediate values in hybrids, as reported by Durkovič et al. 2012 for Sorbus. In Quercus, Himrane et al. (2004) reported a wide spectrum of foliar phenotypes for Q. faginea $x$ Q. pubescens hybrids, including those very close to the parental ones and other intermediate, although these latter ones were very scarce. In our case, only thickness, which is a highly discriminant trait between the parental species, showed an intermediate class between leaves of Q. suber and Q. ilex progenies. Conversely, leaf size and shape of hybrid families in our study were more similar to Q. suber than to Q. ilex, and only the family LG1, mostly pollinated by $Q$. ilex, presented intermediate values for these traits. This result point to differential segregation of genes that regulate leaf size, thickness and shape, and is not surprising, considering that most leaf traits are under polygenic control in oaks (ScottiSaintagne et al. 2004), but also that some of these genes may be pleiotropic (Gailing 2008).

\section{Conclusion}

While fluctuating asymmetry can be detected equally for Q. suber, Q. ilex and hybrid seedlings, a significantly higher proportion of developmental leaf asymmetry is found in hybrid offspring, which would be likely related to higher mortality of the seedlings, accounting for the low frequency of adult hybrid trees in mixed populations. Among the normally developed leaves, thickness was the most discriminant character between species, followed by size and shape. Hybrid offspring leaves show intermediate values, related to the individual genetic composition $\left(q_{s}\right)$, although maternal effects cannot be discarded.

\section{Acknowledgments}

AS and ULH conceived the idea, designed the experiments, collected the plant material and drafted the manuscript; MJD and ULH measured the leaves and performed the statistical analysis. All the authors have contributed to the final manuscript. This work has been funded by the project AGL2015-67495-C2-2-R (Spanish Ministry of Economy and Competitiveness).

\section{References}

Abramoff MD, Magalhaes PJ, Ram SJ (2004). Image processing with ImageJ. Biophotonics International 11 (7): 36-42.

Adams DC, Otárola-Castillo E (2013). geomorph: an $\mathrm{R}$ package for the collection and analysis of geometric morphometric shape data. Methods in Ecology and Evolution 4: 393-399. - doi: 10.1111/2041-210X.12035

Albarrán-Lara AL, Mendoza-Cuenca L, ValenciaAvalos S, González-Rodríguez A, Oyama K (2010). Leaf fluctuating asymmetry increases with hybridization and introgression between 
Quercus magnoliifolia and Quercus resinosa (Fagaceae) through an altitudinal gradient in Mexico. International Journal of Plant Sciences 171 (3): 310-322. - doi: 10.1086/650317

Amaral Franco J (1990). Quercus L. In: "Flora Ibérica” (Castroviejo S, Lainz M, López González G eds). Real Jardín Botánico, CSIC, Madrid, Spain, vol. 12, pp. 15-36. [in Spanish]

Barkoulas M, Galinha C, Grigg SP, Tsiantis M (2007). From genes to shape: regulatory interactions in leaf development. Current Opinion in Plant Biology 10: 660-666. - doi: 10.1016/j.pbi.20 07.07.012

Blue MP, Jensen RJ (1988). Positional and seasonal variation in oak (Quercus, Fagaceae) leaf morphology. American Journal of Botany 75: 939-947. - doi: 10.2307/2443759

Bonhomme V, Picq S, Gaucherel C, Claude J (2014). Momocs: outline analysis using R. Journal of Statistical Software 56 (13): 1-24. - doi: 10.18637/jss.v056.i13

Bruschi P, Vendramin GG, Bussotti F, Grossoni P (2003). Morphological and molecular diversity among Italian populations of Quercus petraea (Fagaceae). Annals of Botany 91 (6): 707-716. doi: 10.1093/aob/mcg075

Burgarella C, Lorenzo Z, Jabbour-Zahab R, Lumaret R, Guichoux E, Petit RJ, Soto A, Gil L (2009). Detection of hybrids in nature: application to oaks (Quercus suber and Q. ilex). Heredity 102: 442-452. - doi: 10.1038/hdy.2009.8

Cardillo E, Bernal CJ (2006). Morphological response and growth of cork oak (Quercus suber L.) seedlings at different shade levels. Forest Ecology and Management 222 (1-3): 296-301. doi: 10.1016/j.foreco.2005.10.026

Castro-Díez P, Puyravaud JP, Cornelissen JHC (2000). Leaf structure and anatomy as related to leaf mass per area variation in seedlings of a wide range of woody plant species and types. Oecologia 124: 476-486. - doi: 10.1007/PL00008 873

Cornelissen JHC (1999). A triangular relationship between leaf size and seed size among woody species: allometry, ontogeny, ecology and taxonomy. Oecologia 118: 248-255. - doi: 10.1007/so 04420050725

Durkovič J, Kardošová M, Canová I, Lagana R, Priwitzer T, Chorvát D, Cicák A, Pichler V (2012). Leaf traits in parental and hybrid species of Sorbus (Rosaceae). American Journal of Botany 99: 1489-1500. - doi: 10.3732/ajb.1100593

Gailing O (2008). QTL analysis of leaf morphological characters in a Quercus robur full-sib family (Q. robur x Q. robur ssp. slavonica). Plant Biology 10 (5): 624-34. - doi: 10.1111/j.1438-8677.20 08.00063.x

Graham JH, Raz S, Hel-Or H, Nevo E (2010). Fluctuating asymmetry: methods, theory, and applications. Symmetry 2: 466-540. - doi: $10.3390 /$ sym2020466

Gugerli F, Walser JC, Dounavi K, Holderegger R, Finkeldey R (2007). Coincidence of small-scale spatial discontinuities in leaf morphology and nuclear microsatellite variation of Quercus petraea and $Q$. robur in a mixed forest. Annals of Botany 99 (4): 713-722. - doi: 10.1093/aob/mc moo6

Harper JL (1977). Population biology of plants. Academic Press, London, UK, pp. 906.

Himrane H, Camarero JJ, Gil-Pelegrín E (2004).
Morphological and ecophy-siological variation of the hybrid oak Quercus subpyrenaica (Q. faginea x Q. pubescens). Trees 18: 566-575. - doi: 10.1007/s00468-004-0340-0

Hódar JA (2002). Leaf fluctuating asymmetry of Holm oak in response to drought under contrasting climatic conditions. Journal of Arid Environments 52: 233-243. - doi: 10.1006/jare.20 02.0989

Kleinschmit JRG, Bacilieri R, Kremer A, Roloff A (1995). Comparison of morphological and genetic traits of pedunculate oak (Q. robur $L$ ) and sessile oak (Q. petraea (Matt) Liebl). Silvae Genetica 44 (5-6): 256-269.

Kozlov MV (2003). Are fast growing birch leaves more asymmetrical? Oikos 101: 654-658. - doi: 10.1034/j.1600-0706.2003.11972.x

Kremer A, Dupouey JL, Deans JD, Cottrell J, Csaikl U, Finkeldey R, Espinel S, Jensen J, Kleinschmit J, Van Dam B, Ducousso A, Forrest I, Lopez De Heredia U, Lowe AJ, Tutkova M, Munro RC, Steinhoff S, Badeau V (2002). Leaf morphological differentiation between Quercus robur and Quercus petraea is stable across western European mixed oak stands. Annals of Forest Sciences 59 (7): 777-787. - doi: 10.1051/for est:2002065

Laguna M (1881). Un mesto italiano y varios mestos espanoles [An Italian "mesto" and several Spanish “mestos"]. Revista Montes 114: 477-486. [in Spanish]

Lodha M, Marco CF, Timmermans MCP (2013). The ASYMMETRIC LEAVES complex maintains repression of KNOX homeobox genes via direct recruitment of Polycomb-repressive complex2. Genes and Development 27: 596-601. - doi: 10.1101/gad.211425.112

López De Heredia U, Sánchez-Pastor H, Soto A (2017). Molecular evidence of bidirectional introgression between Quercus suber and Quercus ilex. iForest [submitted].

Matsumura Y, Ohbayashi I, Takahashi H, Kojima S, Ishibashi N, Keta S, Nakagawa A, Hayashi R, Saéz-Vázquez J, Echeverria $M$, Sugiyama M, Nakamura K, Machida C, Machida Y (2016). A genetic link between epigenetic repressor AS1AS2 and a putative small subunit processome in leaf polarity establishment of Arabidopsis. Biology Open 5 (7): 942-954. - doi: 10.1242/bio.019 109

MCDonald PG, Fonseca CR, Overton JM, Westoby $M$ (2003). Leaf-size divergence along rainfall and soil-nutrient gradients: is the method of size reduction common among clades? Functional Ecology 17: 50-57. - doi: 10.1046/j.1365-243 5.2003.00698.x

Mediavilla S, Escudero A (2003). Leaf life span differs from retention time of biomass and nutrients in the crowns of evergreen species. Functional Ecology 17: 541-548. - doi: 10.1046/j. 1365-2435.2003.00766.x

Mediavilla S, González-Zurdo P, García-Ciudad A, Escudero A (2011). Morphological and chemical leaf composition of Mediterranean evergreen tree species according to leaf age. Trees 25 (4) 669-677. - doi: 10.1007/s00468-011-0544-z Mediavilla S, Gallardo-López V, González-Zurdo $P$, Escudero A (2012). Patterns of leaf morphology and leaf $\mathrm{N}$ content in relation to winter temperatures in three evergreen tree species. International Journal of Biometeorology 56:
915-926. - doi: 10.1007/s0o484-011-0498-2 Mendiburu F, Simon R (2015). Agricolae - Ten years of an open source statistical tool for experiments in breeding, agriculture and biology. PeerJ PrePrints 3: e1748v1. [online] URL: http://peerj.com/preprints/1404/

Milligan J, Krebs R, Mal T (2008). Separating developmental and environmental effects on fluctuating asymmetry in Lythrum salicaria and Penthorum sedoides. International Journal of Plant Sciences 169 (5): 625-630. - doi: 10.1086/ 533600

Nicotra AB, Leigh A, Boyce CK, Jones CS, Niklas KJ, Royer DL, Tsukaya H (2011). The evolution and functional significance of leaf shape in the angiosperms. Functional Plant Biology 38: 535552. - doi: 10.1071/FP11057

Niinemets $U$ (2015). Is there a species spectrum within the world-wide leaf economics spectrum? Major variations in leaf functional traits in the Mediterranean sclerophyll Quercus ilex. New Phytologist 205: 79-96. - doi: 10.1111/nph. 13001

Parsons PA (1990). Fluctuating asymmetry: an epigenetic measure of stress. Biological Reviews of the Cambridge Philosophical Society 65: 131-145. - doi: 10.1111/j.1469-185X.1990.tbo118 6.x

Peguero-Pina JJ, Sancho-Knapik D, Barrón E, Camarero JJ, Vilagrosa A, Gil-Pelegrín E (2014). Morphological and physiological divergences within Quercus ilex support the existence of different ecotypes depending on climatic dryness. Annals of Botany 114 (2): 301-313. - doi: 10.1093/ aob/mcu108

Pinheiro J, Bates D, DebRoy S, Sarkar D (2017). nlme: linear and nonlinear mixed effects models. R package version 3:1-131. [online] URL: https://CRAN.R-project.org/package=nlme Poorter L (2007). Are species adapted to their regeneration niche, adult niche, or both? American Naturalist 169: 433-442. - doi: 10.1086/512 045

Poorter H, Niinemets U, Poorter L, Wright I, Villar R (2009). Causes and consequences of variation in leaf mass per area (LMA): a meta-analysis. New Phytologist 182: 565-588. - doi: 10.1111/j. 1469-8137.2009.02830.x

Pritchard JK, Wen X, Falush D (2010). Documentation for structure software, version 2. 3. Web site. [online] URL: http://web.stanford.edu/ group/pritchardlab/structure.html

Puerta-Piñero C, Gómez JM, Hódar JA (2008). Shade and herbivory induce fluctuating asymmetry in a Mediterranean oak. International Journal of Plant Sciences 169 (5): 631-635. - doi: 10.1086/533601

Quero JL, Villar R, Marañón T, Zamora R (2006). Interactions of drought and shade effects on seedlings of four Quercus species: physiological and structural leaf responses. New Phytologist 170: 819-834. - doi: 10.1111/j.1469-8137.2006.017 13.x

R Core Team (2016). R: a language and environment for statistical computing. R Foundation for Statistical Computing, Vienna, Austria. [online] URL: http://www.R-project.org/

Rieseberg LH, Ellstrand NC (1993). What can molecular and morphological markers tell us about plant hybridization? Critical Reviews in Plant Sciences 12: 213-241. - doi: 10.1080/073526 
89309701902

Rohlf FJ, Slice DE (1990). Extensions of the Procrustes Method for the optimal superimposition of landmarks. Systematic Zoology 39: 4059. - doi: 10.2307/2992207

Sack L, Melcher PJ, Liu WH, Middleton E, Pardee $T$ (2006). How strong is intracanopy leaf plasticity in temperate deciduous trees? American Journal of Botany 93 (6): 829-839. - doi: 10.3732 lajb.93.6.829

Scotti-Saintagne C, Mariette S, Porth I, Goicoechea $P G$, Barreneche $T$, Bodénès $C$, Kremer A (2004). Genome scanning for interspecific differentiation between two closely related oak species (Quercus robur L. and Q. petraea (Matt.) Liebl.). Genetics 168 (3): 1615-1626. - doi: 10.1534/genetics.104.026849

Takanashi H, Marubashi W (2017). Tumorigenesis inheritance from the putative progenitor species of Nicotiana rustica. Plant Biotechnology 34 (2): 79-87. - doi: 10.5511/plantbiotechnology. $17.0413 a$

Tsukaya H (2005). Leaf shape: genetic controls and environmental factors. International Jour- nal of Developmental Biology 49 (5-6): 547-55. doi: $10.1387 / \mathrm{ijdb} .041921 \mathrm{ht}$

Viscosi V (2015). Geometric morphometrics and leaf phenotypic plasticity: assessing fluctuating asymmetry and allometry in European white oaks (Quercus). Botanical Journal of the Linnean Society 179: 335-348. - doi: 10.1111/boj.12 323

Weight C, Parnham D, Waites R (2008). Technical Advance - LeafAnalyser: a computational method for rapid and large-scale analyses of leaf shape variation. The Plant Journal 53 (3): 578586. - doi: 10.1111/j.1365-313X.2007.03330.x Wilsey BJ, Haukioja E, Koricheva J, Sulkinoja M (1998). Leaf fluctuating asymmetry increases with hybridization and elevation in tree-line birches. Ecology 79: 2092-2099. - doi: 10.1890/ 0012-9658(1998)079[2092:LFAIWH]2.0.CO;2

Valladares F, Niinemets U (2008). Shade tolerance, a key plant feature of complex nature and consequences. Annual Review of Ecology, Evolution and Systematics 39: 237-257. - doi: 10.1146/annurev.ecolsys.39.110707.173506

Vaz M, Maroco J, Ribeiro N, Gazarini LC, Pereira
JS, Chaves MM (2011). Leaf level responses to light in two co-occurring Quercus (Quercus ilex and Quercus suber): leaf structure, chemical composition and photosynthesis. Agroforestry Systems 82: 173-181. - doi: 10.1007/s10457-0109343-6

\section{Supplementary Material}

Fig. S1 - Fluctuating seedling asymmetry across cohorts and families.

Fig. S2 - Normal and asymmetric leaves.

Fig. S3 - Developmental seedling asymmetry across cohorts and families.

Fig. S4 - Principal component variation between cohorts.

Fig. S5 - Variance components for the random terms of the models.

Link: Lopez_2577@supploo1.pdf 